\title{
How Role Stress Mediates the Relationship Between Destructive Leadership and Employee Silence: The Moderating Role of Job Complexity
}

\author{
Mengying $\mathrm{Wu}^{1}{ }^{1,2}$ Zhenglong Peng, $^{1}$ and Christophe Estay ${ }^{2}$ \\ ${ }^{1}$ School of Economics and Management, Tongji University, Shanghai, China \\ 2 Department of Management, Kedge Business School, Bordeaux, Talence Cedex, France
}

\begin{abstract}
$\mathrm{D}$ estructive leadership and employee silence have attracted increasing attention in the academy of organisational behaviour and human resource management. However, the research on the mediating mechanism and boundary variables of their relationship has received little attention. The main purpose of our research was to explore the underlying influence of negative leadership (specifically, destructive leadership) on employee silence by developing a moderated mediation model. Drawing from conservation of resources theory, role theory, and the job characteristic model, the new theoretical model concentrates on the role of stress with three dimensions as mediators and the job complexity as a moderator. Using 318 samples collected from multiple companies in southeast China, the model was tested through confirmatory factor analysis, correlation analysis, and the PROCESS program in AMOS and SPSS environments. Results reveal that employees may resort to silence in the workplace due to their feelings of role conflict, role ambiguity, and role overload when they face destructive leadership; while the presence of high job complexity makes the adverse impact of destructive leadership even worse. Managerial and practical implications, limitations, and research directions in future are discussed and offered.
\end{abstract}

Keywords: destructive leadership, role stress, job complexity, employee silence

In modern organisations, many employees make the decision to remain silent about potentially important issues that arise (Tangirala \& Ramanujam, 2008). Despite the fact that employees may have disagreements about workrelated issues, such as the others' rudeness or underlying perils within their organisation, they may not express their opinions and disagreements to their supervisors (Morrison, 2011). A survey by Milliken, Morrison, and Hewlin (2003) found that $85 \%$ of employees had deliberately withheld important work information, and 50\% admitted that talking about organisational problems would make them uncomfortable. In some ways, the silence can be beneficial if it decreases excess information, reduces interpersonal conflicts, and increases information privacy among coworkers (Morrison \& Milliken, 2000). However, in most cases, the employee silence not only hinders information feedback and decision effectiveness, but it also reduces employee satisfaction and job involvement (Dyne, Ang, \& Botero, 2003; Milliken et al., 2003).
Expressing or supressing work information is a decision that every employee has to face every day, and a growing interest has been observed in the reasons for the decisions (Brinsfield, 2013; Xu, Loi, \& Lam, 2015). Previous studies have found that the behaviours or characteristics of leaders are important situational factors that determine employee silence (Edmondson, 2003; Detert \& Burris, 2007). Milliken et al. (2003) argued that some interactions with leaders (such as unsupported leadership, lack of intimacy) led to negative psychological expectations and then affected an employee's silence behaviour. Therefore, in order to explore the impact of destructive leadership on employee silence, the current study aimed to understand the underlying mechanism behind employee silence more thoroughly and to provide guidance for improved management practices.

Hobfoll's (1989) conservation of resources (COR) theory showed subordinates caught in a stress situation may engage in regulative tactics (i.e., attempt to maintain 


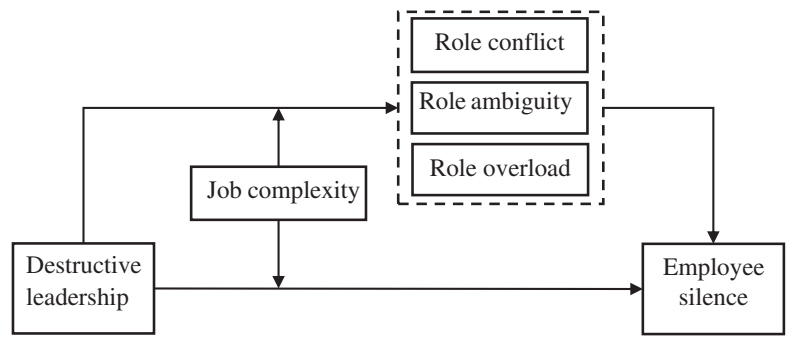

Figure 1

Conceptual model.

relationships by avoiding contact) and feedback avoidance behaviours (i.e., attempt to intentionally evade feedback from the supervisor) to select or create a comfortable environment to minimise the loss of their resources (Tepper, Moss, Lockhart, \& Carr, 2007; Whitman, Halbesleben, \& Holmes, 2014). In an employee's daily routine, apathy, ridicule and abuse from a supervisor will significantly reduce the subordinate's perceptions of their leader's consideration and participation, and subsequently increase their role stress (Teas, 1983; Dale \& Fox, 2008). At this point, they need to use significant emotional resources to cope with their supervisors and deal with the stress, and keeping silence is a major way to preserve their emotional resources and achieve effective survival (Xu et al., 2015). In addition, although high job complexity means that subordinates need to obtain ample work information (Hunter, Schmidt, \& Judiesch, 1990), they are likely to suffer from a lack of information when they are faced with destructive leadership (Schyns \& Schilling, 2013). Meanwhile, conflicting information or not knowing what's expected of them may result in subordinates experiencing unpredictability or possible role stress (Teas, 1983; Dale \& Fox, 2008). Therefore, we postulate that destructive leadership in high job complexity may be more imperilling to subordinates' resources, which culminates in heightened role stress and silence behaviour. Figure 1 presents our conceptual model.

Our research makes the following contributions. First, our study attempted to establish the relationship between destructive leadership and employee silence by examining why and in which contexts such leadership behaviour affects employees' silence behaviour in the workplace (Park, Carter, DeFrank, \& Deng, 2016). We answered the call of a previous study for more research on subordinates' passive responses by conducting an experimental study that examined the influence process of destructive leadership on employee silence via role stress (Tepper et al., 2007; Restubog, Scott, \& Zagenczyk, 2011). It is one of the few studies that has examined the three dimensions of role stress as mediators in the effect of such a negative leadership behaviour on employee silence (Mackey, Frieder, Brees, \& Martinko, 2015). Second, our research makes important contributions to the extant silence literature by investigating the antecedents and contextual factors of employee silence and identifying the potential moderating effects of job complexity. Most studies suggest that job complexity is a positive factor for employee behaviour (Jung, Nam, Lee, \& Kim, 2016; Mohan \& Mulla, 2013; Tierney \& Farmer, 2002), but we found a different result when simultaneously taking destructive leadership and job complexity into account to examine their interactive impact on employee behaviour. Third, our study broadens the current literature on the deleterious impacts of destructive leadership. Although destructive leadership is common and highly dysfunctional in the workplace, the research on the consequences of destructive leadership needs to be further explored (Einarsen, Aasland, \& Skogstad, 2007). We responded to the call to pay attention to the crippling impact of abusive supervision and provide some suggestions for organisations to help prevent silence behaviour (Xu et al., 2015).

\section{Theoretical Background and Hypotheses} Destructive Leadership and Employee Silence

Scholars have been discussing the negative characteristics of personal charisma for a long time, and more researchers have been paying attention to various forms of destructive leadership and their negative effects (Einarsen et al., 2007). When employees experience destructive leadership, they have to spend more time and energy to struggle, survive, and preserve their limited resources, and thus they remain silent (Park et al., 2016). Because a leader is the recipient and disposer of the employees' opinions and voice within organisations, various motivations may cause individuals to rarely report or express their concerns and opinions on job-related issues to their supervisors (Dedahanov et al., 2016). From the perspective of COR theory (Hobfoll 1989), when subordinates are under a destructive leadership, they need to consume time and energy to cope with the stressful workplace event, instead of focusing on finding work problems and reporting them. Meanwhile, when destructive leadership depletes the employees' resources, they will be more inclined to stay silent to protect their own resources (Halbesleben, Neveu, PaustianUnderdahl, \& Westman, 2014; Park et al., 2016). Furthermore, employees tend to remain silent if the leaders are not interested in or hold a negative attitude to the advice and comments the employees offer (Vakola \& Bouradas, 2005). When employees are aware that their voice may breed some risks or have an impact on their interpersonal relationships, they may become reluctant to speak up (Fuller, Marler, \& Hester, 2006). Therefore, we believe that destructive leadership contributes to individuals' decisions to share their concerns or keep silent. Thus, we offer the following hypothesis:

Hypothesis 1: Destructive leadership is positively related to employee silence.

\section{The Mediating Effect of Role Stress}

Role theory can interpret employees' mentality, behaviour, and transition through their social role, and can reveal the 
individuals' different roles in the organisational context (Tubre \& Collins, 2000; Walker, Churchil, \& Ford, 1975). When the perceptions of individual roles are uncontrolled, employees' roles may become ineffective and create role stressors (Walker et al., 1975). Role stressors are conceptualised as role conflict, role ambiguity, and role overload using three constructs (Belasco, 1966; Behrman \& Perreault, 1984). Role conflict occurs when an employee perceives that the 'real role' and 'expected role' are incompatible; role ambiguity refers to the confusion of role expectations because of absent information or uncertainty about different role expectations; role overload is related to employees' cumulative role tasks that exceed his or her abilities and it means they may be unable to finish the tasks in time (Conley \& You, 2014; Singh, 1998).

The role episode model of Kahn, Wolfe, Quinn, Snoek, and Rosenthal (1964) suggests that employees who are unable to clearly distinguish the appropriate expectations and standards that are held by others or caused from their own behaviour may develop role stress. Employees' perceptions of stress may be influenced by their cognitive ability, mental ability, social factors, and personal characteristics; while the instructions and requirements of destructive leadership can cause role conflict, role ambiguity, and role overload for employees (Singh, 1998). For instance, when the expectations of destructive leadership are inconsistent with organisational goals, employees' role conflicts will be increased (Teas, 1983; Tubre \& Collins, 2000). Subordinates who are ridiculed and belittled by their supervisors may not have enough information available to them. They may not clearly understand the expectations of their leader, which can result in a lack of expectations for their own behaviours and an increase in role ambiguity (Singh, 1993; Tubre \& Collins, 2000). Employees who are believed to be incompetent or stupid by leaders are often unable to complete difficult tasks by a set time or in specific conditions, and if they are given more role tasks than other employees, they may feel role overload (Peterson et al., 1995). Thus, we consider that destructive leadership is positively related to role stress of employees.

Moreover, COR theory provides an explanation for the mediating mechanism of role stress on destructive leadership and employee silence (Ng \& Feldman, 2012; Xu et al., 2015). Past consensual evidence has demonstrated that role stressors have a negative effect on employees' attitudes and behaviours (Brown \& Peterson 1993). Stressed individuals may be motivated to preserve their limited resources by avoiding actions (i.e., silence behaviour) to prevent their remaining resources being depleted (Hobfoll, 1989, 2001). Employees in role conflict may worry about being marked as complainers or troublemakers and thus lose desirable personal resources or career opportunities and, as a result, they do not speak up (Detert \& Treviño, 2010). The employees in role ambiguity due to being abused by destructive leadership may remain silent because their voice will take more of their available resources and they will face more risk of future resource depletion (Ng \& Feldman, 2012). Further, employees who experience role overload will try to retain their remaining resources when they are exhausted, and silence is a natural and safe way to protect themselves (Morrison, 2011). Accordingly, employees with role stress are motivated to minimise the adverse effects of stressors (Xu et al., 2015). They will not consume their remaining resources to change the status quo, even though it may improve their work circumstances (Ng \& Feldman, 2012). Moreover, even when they are conscious of the fact that silence is detrimental to the development of organisations, they still adopt silence to isolate themselves from the work to protect their limited valuable resources and prevent further resource loss (Bolton, Harvey, Grawitch, \& Barber, 2012). Thus, we suggest the following hypotheses:

\begin{abstract}
Hypothesis 2a: Role conflict mediates the positive relationship between destructive leadership and employee silence.

Hypothesis $2 b$ : Role ambiguity mediates the positive relationship between destructive leadership and employee silence. Hypothesis 2c: Role overload mediates the positive relationship between destructive leadership and employee silence.
\end{abstract}

\section{The Moderating Effect of Job Complexity}

Job complexity is characterised by high autonomy, identity, feedback, skill variety and significance, which constitute the job characteristics model (Hackman \& Oldham, 1975, 1980). Complex tasks make employees tend to express greater intrinsic motivation to develop work devotion and feel that their job is meaningful and important (Wang, Tsai, \& Tsai, 2014). Meanwhile, destructive leadership denotes specific supervisor behaviour that is perceived as hostile and/or obstructive by the employee (Schyns \& Schilling, 2013). Thus, job complexity and destructive leadership can coexist as different perspectives in the perceptions and actions of the employee (Coelho, Augusto, \& Lages 2011). Furthermore, although employees with different levels of job complexity may be affected by destructive leadership, those with more complex tasks may be more likely to perceive and remember destructive leadership (Wang et al., 2014). Therefore, our study supported destructive leadership and job complexity as two independent variables, and job complexity was a moderating variable.

According to the results of Tepper (2000) and Tepper et al. (2007), the influence of negative leadership on subordinate behaviour and attitudes may be affected by job characteristics. From the perspective of COR theory, employees in complex jobs have more resources and higher levels of intrinsic motivations, and they are more likely to speak up than keep silent under the same conditions (Bakker \& Demerouti, 2007). However, if they speak up and simultaneously encounter destructive leadership, they may lose those resources or be transferred to a less complex job, and they will therefore tend to keep silent in this situation (Hakanen, Bakker, \& Demerouti, 2005). On the contrary, although those who work in less complex jobs possess relatively fewer resources and weak internal 
motivation, they tend to keep a lower frequency of silence as a way to get additional resources when they face destructive leadership (Einarsen et al., 2007; May, Wesche, Heinitz, \& Kerschreiter, 2015). As a result, employees who are engaged in a high level of job complexity are more likely to remain silent than employees who are engaged in less complex jobs when they experience destructive leadership. Thus, we put forward the following hypothesis:

Hypothesis 3: Job complexity moderates the positive relationship between destructive leadership and employee silence, and this relationship is stronger when job complexity is high rather than low.

Incompatibile information sources may form an uncontrollable and unpredictable work context (Greenbaum, Mawritz, \& Piccolo, 2015), where employees' role stress will more likely occur (Tubre \& Collins; 2000). In an organisation, job complexity can motivate employee performance (Wang et al., 2014; Nurmi \& Hinds, 2016), but it can also create hostility or obstructive behaviour (May et al., 2015). When these two situations occur simultaneously, employees may experience the psychological uneasiness of cognitive dissonance and feel greater role conflict (Coelho et al., 2011). Similarly, with destructive leadership, employees with complex jobs may be more likely to experience role ambiguity than those with less complex jobs (Jackson \& Schuler, 1985) because job complexity entails more autonomy, and if there is a lack of focus and work formalisation, it may lead to increased levels of role ambiguity (Organ \& Greene, 1981; Rousseau, 1978; Sorenson \& Sorenson, 1974). In addition, the motivational force of the job complexity may cause an overstimulation effect under destructive leadership (Singh, 1998). Too much complexity in jobs can be perceived as information overload and make employees feel role overload (Singh, 1998). Consequently, a high level of job complexity with destructive leadership may result in more role stress than those in less complex jobs. Accordingly, we propose the following hypotheses:

Hypothesis 4a: Job complexity moderates the positive relationship between destructive leadership and role conflict, and such a relationship is stronger when job complexity is high rather than low.

Hypothesis 4b: Job complexity moderates the positive relationship between destructive leadership and role ambiguity, and such a relationship is stronger when job complexity is high rather than low.

Hypothesis $4 c$ : Job complexity moderates the positive relationship between destructive leadership and role overload, and such a relationship is stronger when job complexity is high rather than low.

From these assumptions, we further put forward the moderated mediation model analysis of job complexity; specifically, that the three dimensions of role stress (i.e., role conflict, role ambiguity, and role overload) mediate the positive effect of destructive leadership on employee silence. Job complexity not only moderates the relationship between destructive leadership and the three dimen- sions of role stress, but also moderates the relationship between destructive leadership and employee silence. Accordingly, we propose a moderated mediation model using the method of Preacher, Rucker, and Hayes (2007). We expect that destructive leadership's indirect effect on employee silence through the three dimensions of role stress also depends on the level of job complexity. Thus, we offer the following hypotheses:

\begin{abstract}
Hypothesis 5a: Job complexity moderates the strength of the indirect effect of destructive leadership on employee silence via role conflict, such that the mediated relationship is stronger when job complexity is high rather than low.

Hypothesis 5b: Job complexity moderates the strength of the indirect effect of destructive leadership on employee silence via role ambiguity, such that the mediated relationship is stronger when job complexity is high rather than low.

Hypothesis $5 c$ : Job complexity moderates the strength of the indirect effect of destructive leadership on employee silence via role overload, such that the mediated relationship is stronger when job complexity is high rather than low.
\end{abstract}

\section{Method}

\section{Sample and Procedure}

The data were collected in Shanghai Municipality and Hangzhou City in China from October to December 2016. With the assistance of the management committees of two industries, we randomly selected 12 manufacturing firms to conduct a questionnaire survey. Our team contacted the human resources management department of each company, and received their support. With the help of the HR managers, we selected permanent staff under a direct leader as the research target. In order to avoid common method variance, we paired the sample by randomly selecting 3-6 leaders with 3-8 of the direct subordinates in each firm. The leader filled out the questionnaire first and marked the employees' number, and then our research members found the corresponding employees to complete their questionnaires. Meanwhile, in order to reduce social desirability bias, we recorded the purposes and details of the survey and the voluntary nature of participation in the cover page of the questionnaire. We also assured anonymity and confidentiality to the participants and provided the contact information of the first author. Respondents were required to complete the questionnaires alone during working hours and return them in sealed envelopes. In this survey, all questionnaires of the model variables were filled out by subordinates. The leader only needed to complete basic information to serve as a reference for the subordinates' evaluation. We distributed questionnaires to 96 supervisors and 426 subordinates, and of these, 82 and 352 respectively were returned. After excluding invalid and obvious abnormal questionnaires, there were 318 completed and valid samples from the 352 returned, representing an overall response rate of $74.65 \%$. In this sample, $58.18 \%$ were male, $68.55 \%$ were aged from 26 to 40 , the mean working time was 5.49 years, and $44.97 \%$ had received a university degree or higher. 


\section{Measures}

Destructive leadership. We used a five-item scale developed and validated by Mitchell and Ambrose (2007) to assess destructive leadership. Sample items are 'My supervisor ridicules me' and 'My supervisor tells me my thoughts or feelings are stupid'. Response options range from $1=$ never, to $5=$ always. Cronbach's alpha for this scale is 0.84 .

Role stress. We referred to the role stress measurement index system designed by Peterson et al. (1995) and measured role conflict with three items, role ambiguity with five items, and role overload with five items. A sample item of role conflict is 'I often have to face some conflicting situations'. A sample item of role ambiguity is 'I know what my job is'. A sample item of role overload is 'I feel a heavy burden on my work. Response options range from $1=$ never, to $5=$ always. It is worth mentioning that the scale of the role ambiguity are reverse items, and we carried out the reverse score processing in order to ensure the internal consistency of the role stress scale. The scale's reliability of role conflict, role ambiguity, and role overload are 0.82 , 0.90 , and 0.75 respectively.

Job complexity. We measured job complexity using a fouritem scale adapted from a well-validated German scale (Zapf, 1993) that is widely used in Western countries. Sample items include: 'Do you receive tasks that are extraordinary and particularly difficult?' and 'Can you use all your knowledge and skills in your work?. Response options range from $1=$ very little, to $5=$ very much. The scale's reliability is 0.72 .

Employee silence. We used a five-item scale designed by Dyne (2003) to assess employee silence. Sample items include: 'Although I have ideas or suggestions to improve my work, I don't say it' and 'The problems are caused by the communication between leaders and employees, and I will not mention'. Response options range from $1=$ strongly disagree to $5=$ strongly agree. Cronbach's alpha for this scale is 0.86 .

Control variables. Because all the respondents in our research were frontline employees, we controlled participants' gender, age, education, and working time to be consistent with previous research (Hofmann, Schmeichel, \& Baddeley, 2012; Tangirala \& Ramanujam, 2008). Gender was a dummy variable, and males were 0 and females were 1 . Age was coded as $1=25$ or below, $2=26-35,3=$ $36-45,4=46$ or above. Working time was coded as $1=1$ year or below, $2=2-5$ years, $3=6-9$ years, $4=9$ years or above. Education was coded as $1=$ high school or under, $2=$ vocational school, $3=$ university, $4=$ graduate school .

\section{Results}

\section{Confirmatory Factor Analysis (CFA)}

We applied AMOS 21.0 to conduct confirmatory factor analysis of all variables for ensuring the rationality of the data structure. The discriminant validity of each scale was tested by comparing $\chi^{2} / d f$ and the comparative fit index (CFI), Tucker Lewis index (TLI), incremental fit index (IFI), goodness-of-fit index GFI, and root mean square error of approximation (RMSEA). As shown in Table 1, compared with other models, the six-factor model with 27 items fit our data better than the alternative models, which yielded a poor fit to the data. The data for $\chi^{2}$ of $788.59(d f=297, p<.01)$, CFI of 0.92, TLI of 0.91, IFI of 0.92, and RMSEA of 0.07 with the inspection of factor loadings and factor covariance suggest that all factor loadings were significant, demonstrating convergent validity. In addition, the baseline six-factor model has a significant improvement in $\chi^{2}$ (model $1, \Delta \chi^{2}(3)=253.03, p<.01$; model $2, \Delta \chi^{2}(5)=456.89, p<.01$; model $3, \Delta \chi^{2}(6)=$ 458.41, $p<.01$; model $\left.4, \Delta \chi^{2}(7)=780.44, p<.01\right)$, which were a better fit to our data than the other alternative measurement models. Thus, the discriminant validity of the constructs was clear and suitable for the correlation analysis.

\section{Descriptive Statistics}

Table 2 reports means, standard deviations, and correlations of the variables. As predicted above, destructive leadership was positively related to employee silence $(r=$ $.20, p<.01)$, and significantly affects role conflict $(r=$ $.24, p<.01)$, role ambiguity $(r=.15, p<.01)$, and role overload $(r=.26, p<.01)$. Hypothesis 1 is supported initially and provides a basis for further analysis. Otherwise, consistent with our expectations, job complexity was not related to destructive leadership $(r=.04, p>0.05)$ but positively related to role conflict $r=.34, p<.01$ ), role ambiguity $(r=.21, p<.01)$, and role overload $(r=.33, p$ $<.01)$.

\section{Hypotheses Tests}

Table 3 shows the results of the mediating effect and the moderating effect generated by the PROCESS macro suggested by Hayes (2013). We used model 4 in a PROCESS macro to test the mediation effect. According to Baron and Kenny's (1986) suggestions, as can be seen from the test of mediation effect, destructive leadership is positively related to employee silence $(\beta=0.22, p<.01)$, which further supports hypothesis 1 . When we include the mediator in the model, we can see that role conflict is still positively associated with employee silence $(\beta=0.50, p<$ $.01)$, whereas the relationship between destructive leadership and employee silence is no longer significant $(\beta=$ $0.06, p>.05$ ); role ambiguity is still positively associated with employee silence $(\beta=0.45, p<.01)$, whereas the relationship between destructive leadership and employee silence significantly declines $(\beta=0.16, p<.05)$; and role overload is still positively associated with employee silence ( $\beta=0.69, p<.01)$, whereas the relationship between destructive leadership and employee silence is no longer significant $(\beta=0.06, p<.05)$. Also, the Sobel test proved that the indirect effect $(a b)$ is statistically significant (role 
Table 1

Results of Confirmatory Factor Analysis of the Measurement Models

\begin{tabular}{llllllll}
\hline \multicolumn{2}{l}{ Measurement models } & $\chi^{2}(d f)$ & $\Delta \chi^{2}(\Delta d f)$ & $\mathrm{CFI}$ & $\mathrm{TLI}$ & IFI & RMSEA \\
\hline Six-factor & $\mathrm{DL}, \mathrm{RC}, \mathrm{RA}, \mathrm{RO}, \mathrm{JC}, \mathrm{ES}$ & $788.59(297)^{* *}$ & - & 0.92 & 0.91 & 0.92 & 0.07 \\
Five-factor & $\mathrm{DL}, \mathrm{RC}+\mathrm{RA}, \mathrm{RO}, \mathrm{JC}, \mathrm{ES}$ & $1041.62(300)^{* *}$ & $253.03(3)^{* *}$ & 0.87 & 0.84 & 0.87 & 0.09 \\
Four-factor & $\mathrm{DL}, \mathrm{RC}+\mathrm{RA}+\mathrm{RO}, \mathrm{JC}, \mathrm{ES}$ & $1245.48(302)^{* *}$ & $456.89(5)^{* *}$ & 0.83 & 0.80 & 0.83 & 0.10 \\
Three-factor & $\mathrm{DL}, \mathrm{RC}+\mathrm{RA}+\mathrm{RO}, \mathrm{JC}+\mathrm{ES}$ & $1247.00(303)^{* *}$ & $458.41(6)^{* *}$ & 0.83 & 0.80 & 0.83 & 0.10 \\
Two-factor & $\mathrm{DL}+\mathrm{ES}, \mathrm{RC}+\mathrm{RA}+\mathrm{RO}+\mathrm{JC}$ & $1569.03(304)^{* *}$ & $780.44(7)^{* *}$ & 0.77 & 0.75 & 0.77 & 0.11 \\
\hline
\end{tabular}

Note: $\mathrm{DL}=$ destructive leadership; $\mathrm{RC}=$ role conflict; $\mathrm{RA}=$ role ambiguity; $\mathrm{RO}=$ role overload; $\mathrm{JC}=$ job complexity; $\mathrm{ES}=$ employee silence;

"+" means two factors are combined into one factor. ${ }^{* *} p<.01 ;{ }^{*} p<.05$.

Table 2

Means, Standard Deviation, and Correlations of Variables

\begin{tabular}{|c|c|c|c|c|c|c|c|c|c|c|c|c|c|}
\hline & & $M$ & $S D$ & 1 & 2 & 3 & 4 & 5 & 6 & 7 & 8 & 9 & 10 \\
\hline 1 & Gender & 1.58 & 0.50 & - & & & & & & & & & \\
\hline 2 & Age & 1.95 & 0.68 & $-020^{* *}$ & - & & & & & & & & \\
\hline 3 & Education & 2.36 & 0.79 & 0.10 & -005 & - & & & & & & & \\
\hline 4 & Working time & 2.62 & 1.02 & -012 & $0.69 * *$ & $-020 * *$ & - & & & & & & \\
\hline 5 & $\begin{array}{l}\text { Destructive } \\
\quad \text { leadership }\end{array}$ & 3.26 & 0.71 & 0.11 & -007 & -009 & -001 & $(0.84)$ & & & & & \\
\hline 6 & Role conflict & 3.13 & 0.97 & -002 & 0.06 & $-018 * *$ & 0.01 & $0.24^{* *}$ & $(0.82)$ & & & & \\
\hline 7 & Role ambiguity & 3.68 & 0.74 & 0.10 & $-014^{* *}$ & -005 & $-013^{* *}$ & $0.15^{* *}$ & $0.39 * *$ & $(0.90)$ & & & \\
\hline 8 & Role overload & 3.38 & 0.66 & 0.01 & 0.04 & $-017^{* *}$ & -001 & $0.26^{* *}$ & $0.48^{* *}$ & $0.49 * *$ & $(0.75)$ & & \\
\hline 9 & Job complexity & 3.16 & 0.91 & -003 & 0.01 & -011 & -007 & 0.04 & $0.34^{* *}$ & $0.21 * *$ & $0.33^{* *}$ & $(0.72)$ & \\
\hline 10 & Silence & 3.09 & 0.86 & 0.04 & -001 & $-020 * *$ & -001 & $0.20^{* *}$ & $0.60^{* *}$ & $0.42^{* *}$ & $0.56^{* *}$ & $0.41^{* *}$ & $(0.86)$ \\
\hline
\end{tabular}

Note: $\mathrm{M}=$ mean, $S D=$ standard deviation. ${ }^{* *} p<.01 ;{ }^{*} p<.05$. Cronbach's $\alpha$ reliability coefficients appear on the diagonal.

conflict: effect size $=0.17, S E=0.04, z=4.21,95 \%$ CI $[0.09,0.25], p<.01$; role ambiguity: effect size $=0.07$, $S E=0.03, z=2.32,95 \%$ CI $[0.02,0.14], p<.05$; role overload: Effect size $=0.17, S E=0.04, z=4.22,95 \%$ CI $[0.09$, 0.26 ],$p<.01)$. The results with a bootstrapped $99 \%$ confidence interval around the indirect effect not containing zero (role conflict: $0.07 \sim 0.28$; role ambiguity: $0.01 \sim$ 0.17; role overload:0.07 0.29) confirmed the Sobel test (MacKinnon, Lockwood, \& Williams, 2004). Therefore, role conflict and role overload fully mediated the positive relationship between destructive leadership and employee silence, and role ambiguity partly mediated the positive relationship between the two. Thus, hypotheses $2 \mathrm{a}, 2 \mathrm{~b}$, and $2 \mathrm{c}$ are supported.

We used model 1 in a PROCESS macro to test moderation effect. From the test of moderation effect shown in Table 2, the interaction of destructive leadership with job complexity had a significant effect on employee silence $(\beta=0.31, p<.01)$, role conflict $(\beta=0.23, p<.01)$, role ambiguity $(\beta=0.23, p<.01)$, and role overload $(\beta=$ $0.17, p<.05)$. This illustrates that hypotheses $3,4 \mathrm{a}, 4 \mathrm{~b}$, $4 \mathrm{c}$ are supported. Furthermore, in order to obtain a more intuitive response, the interaction effects of job complexity at different levels (i.e., one standard deviation above or below the mean level), we plotted the moderating effect figure following the recommendation of Aiken and West (1991). Figures 2, 3, 4, and 5 show that the positive relationship between destructive leadership and employee silence, and the positive relationship between destructive leadership and the three dimensions of role stress are relatively stronger in high job complexity rather than low.

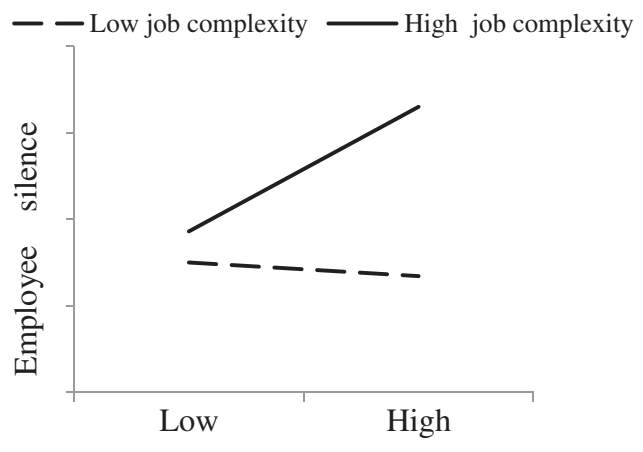

Figure 2

Job complexity as a moderator of destructive leadership and employee silence.

The above analysis has laid the foundation for the development of a moderated mediation model. In the last part of Table 3, we used model 8 in a PROCESS macro to test the moderated mediation effect. The conditional indirect effect of destructive leadership on employee silence through role conflict, role ambiguity, and role overload are stronger and significant for high job complexity (effect size $=0.21,0.13,0.21,95 \%$ bias-corrected confidence interval from 0.11 to $0.32,0.05$ to $0.23,0.11$ to 0.34 , without zero) but weaker and not significant for low job complexity (effect size $=0.07,-0.02,0.06,95 \%$ biascorrected confidence interval from -0.02 to $0.16,-0.08$ to $0.05,-0.01$ to 0.16 , containing zero). Consequently, our theoretical model satisfies conditions of the moderated mediation effect, and hypotheses $5 \mathrm{a}, 5 \mathrm{~b}, 5 \mathrm{c}$ are supported and validated. 
Table 3

Conditional process analysis

\begin{tabular}{|c|c|c|c|c|c|c|}
\hline \multicolumn{4}{|c|}{ Test of Mediation Effect } & $S E$ & & $p$ \\
\hline \multicolumn{3}{|c|}{ Destructive leadership $\rightarrow$ Employee silence } & $0.22^{* *}$ & 0.07 & 3.26 & $<.01$ \\
\hline \multirow{2}{*}{\multicolumn{3}{|c|}{$\begin{array}{l}\text { Destructive leadership } \rightarrow \text { Employee silence } \\
\text { Role conflict } \rightarrow \text { Employee silence }\end{array}$}} & 0.06 & 0.05 & 1.10 & $>.05$ \\
\hline & & & $0.50^{* *}$ & 0.05 & 10.91 & $<.01$ \\
\hline \multicolumn{3}{|c|}{$\begin{array}{l}\text { Destructive leadership } \rightarrow \text { Employee silence } \\
\text { Role ambiquity } \rightarrow \text { Employee silence }\end{array}$} & $0.16^{*}$ & 0.07 & 2.40 & $<.05$ \\
\hline \multirow{2}{*}{\multicolumn{3}{|c|}{$\begin{array}{l}\text { Role ambiguity } \rightarrow \text { Employee silence } \\
\text { Destructive leadership } \rightarrow \text { Employee silence }\end{array}$}} & $0.45^{* *}$ & 0.07 & 6.57 & $<.01$ \\
\hline & & & 0.06 & 0.06 & 0.96 & $>.05$ \\
\hline \multicolumn{3}{|l|}{ Role overload $\rightarrow$ Employee silence } & $0.69 * *$ & 0.06 & 10.65 & $<.01$ \\
\hline Sobel test & Effect & $S E$ & $\mathrm{LL} 95 \% \mathrm{Cl}$ & UL $95 \% \mathrm{Cl}$ & $z$ & $p$ \\
\hline role conflict & 0.17 & 0.04 & 0.09 & 0.25 & 4.21 & $<.01$ \\
\hline role ambiguity & 0.07 & 0.03 & 0.02 & 0.14 & 2.32 & $<.05$ \\
\hline role overload & 0.17 & 0.04 & 0.09 & 0.26 & 4.22 & $<.01$ \\
\hline Bootstrap result for indirect effect & Effect & SE & $\mathrm{LL} 99 \% \mathrm{Cl}$ & UL $99 \% \mathrm{Cl}$ & & \\
\hline role conflict & 0.17 & 0.04 & 0.07 & 0.28 & & \\
\hline role ambiguity & 0.07 & 0.03 & 0.01 & 0.17 & & \\
\hline role overload & 0.17 & 0.04 & 0.07 & 0.29 & & \\
\hline \multicolumn{7}{|l|}{ Test of Moderation Effect } \\
\hline \multicolumn{3}{|c|}{ Regression Results for Simple Moderation } & $\beta$ & $S E$ & $t$ & $p$ \\
\hline \multicolumn{3}{|c|}{ Job complexity $\rightarrow$ Employee silence } & $0.32^{* *}$ & 0.05 & 6.30 & $<.01$ \\
\hline \multicolumn{3}{|c|}{ Destructive leadership $\times$ Job complexity } & $0.31^{* *}$ & 0.72 & 4.26 & $<.01$ \\
\hline \multicolumn{3}{|l|}{ Job complexity $\rightarrow$ Role conflict } & $0.29 * *$ & 0.06 & 4.75 & $<.01$ \\
\hline \multicolumn{3}{|c|}{ Destructive leadership $\times$ Job complexity } & $0.23 *$ & 0.10 & 2.20 & $<.05$ \\
\hline \multicolumn{3}{|l|}{ Job complexity $\rightarrow$ Role ambiguity } & $0.13^{* *}$ & 0.05 & 2.63 & $<.01$ \\
\hline \multicolumn{3}{|c|}{ Destructive leadership $\times$ Job complexity } & $0.23 * *$ & 0.08 & 2.98 & $<.01$ \\
\hline \multicolumn{3}{|l|}{ Job complexity $\rightarrow$ Role overload } & $0.19^{* *}$ & 0.04 & 4.42 & $<.01$ \\
\hline \multicolumn{3}{|c|}{$\begin{array}{l}\text { Destructive leadership } \times \text { Job complexity } \\
\text { Test of Moderated Mediation Effect }\end{array}$} & $0.17^{* *}$ & 0.07 & 2.37 & $<.01$ \\
\hline \multirow{2}{*}{\multicolumn{3}{|c|}{$\begin{array}{l}\text { Test of Moderated Mediation Effect } \\
\text { Bootstrap result for indirect effect }\end{array}$}} & & & & \\
\hline & & & Effect & $S E$ & LL 95\% Cl & UL 95\% Cl \\
\hline \multirow[t]{2}{*}{ role conflict } & \multicolumn{2}{|c|}{ Low (-1 SD) } & 0.07 & 0.05 & -002 & 0.16 \\
\hline & \multicolumn{2}{|c|}{ High (+1 SD) } & 0.21 & 0.05 & 0.11 & 0.32 \\
\hline \multirow{2}{*}{ role ambiguity } & \multicolumn{2}{|c|}{ Low (-1 SD) } & -002 & 0.03 & -008 & 0.05 \\
\hline & \multicolumn{2}{|c|}{ High (+1 SD) } & 0.13 & 0.04 & 0.05 & 0.23 \\
\hline \multirow[t]{2}{*}{ role overload } & \multicolumn{2}{|c|}{ Low (-1 SD) } & 0.06 & 0.04 & -001 & 0.16 \\
\hline & \multicolumn{2}{|c|}{ High (+1 SD) } & 0.21 & 0.06 & 0.11 & 0.34 \\
\hline
\end{tabular}

Note: ${ }^{* *} p<.01: * p<.05$. Unstandardised regression coefficients were reported. Bootstrap sample size $=5,000$. LL $=$ lower limit, UL $=$ upper limit, $\mathrm{Cl}=$ confidence interval. Bias-corrected $\mathrm{Cl}$ is reported. Low $=1 S D$ below the mean; High $=1 S D$ above the mean.

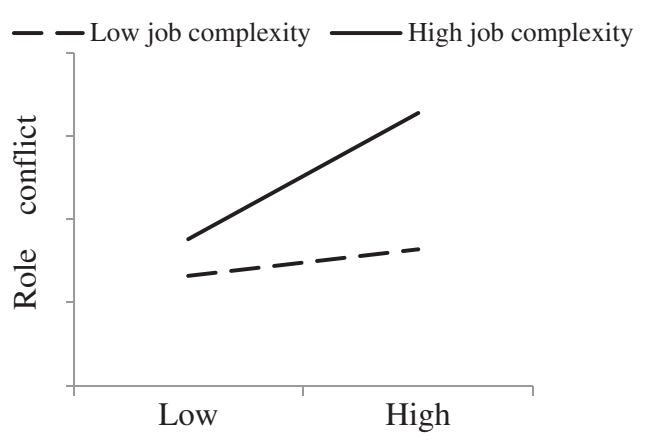

\section{Figure 3}

Job complexity as a moderator of destructive leadership and role conflict.

\section{Discussion}

\section{Theoretical Implications}

The theoretical contributions in our study include the following two aspects. First, our study attempted to extend the silence literature by shedding light on the mediating mechanism of role stress on the relationship between de-

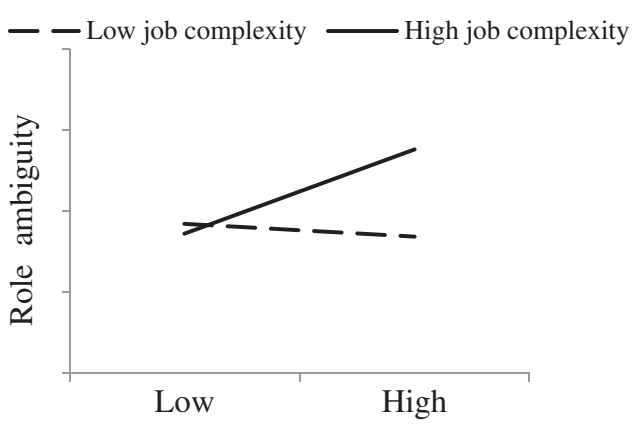

\section{Figure 4}

Job complexity as a moderator of destructive leadership and role ambiguity.

structive leadership and employee silence. Although previous studies have reviewed the negative outcomes and effects of destructive leadership (e.g., Schyns \& Schilling, 2013; Thoroughgood, Padilla, Hunter, \& Tate, 2012), the literature about the antecedents and underlying mechanism of silence triggered by destructive leadership is still limited (Martinko, Harvey, Brees, \& Mackey, 2013; Mackey 


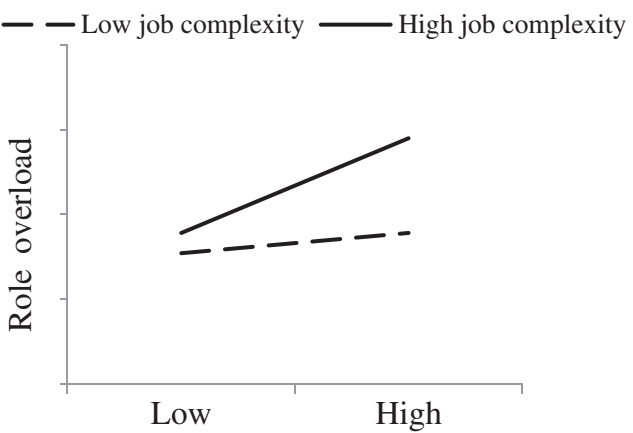

Figure 5

Job complexity as a moderator of destructive leadership and role overload.

et al., 2015). Some studies have examined the mediating mechanism of destructive leadership on employee silence and its detrimental psychological consequences (e.g., psychological distress, fear, emotional exhaustion; Kiewitz, Restubog, Shoss, Garcia, \& Tang, 2016; Xu et al., 2015), but the linkage of the 'destructive leadership role' and 'stress-employee silence' has not been established, and this study is the first to investigate the mediating mechanism of role conflict, role ambiguity, and role overload between destructive leadership and employee silence. Accordingly, our findings indicate that, drawing on COR theory and role theory, destructive leadership depletes employees' resources by shaping a high level of role conflict, role ambiguity and role overload, which can result in employee silence. The research provides a strong basis to understand more deeply the motivating mechanism behind employee silence and expands the path of the existing research on the relationship between destructive leadership and employee silence.

Second, another contribution of this work is that the examination of job complexity as a new explanatory variable enriches the extant silence literature and provides a different perspective to understand the moderating mechanism on the relationship between destructive leadership and role stress (Farh \& Chen, 2014). We found that complex jobs do not motivate employee behaviours when they experience destructive leadership. That is to say, destructive leadership for high-level job complexity is more beneficial to role stress than for less complex jobs. This conclusion is not consistent with the argument that job complexity has a positive influence on employee behaviour (Mohan \& Mulla, 2013; Jung et al., 2016). We developed previous research by combining COR theory and the job characteristics model to link destructive leadership concurrently with job complexity to other organisational consequences (i.e., role stress, employee silence). Accordingly, we further inferred that job complexity may not necessarily promote positive outcomes. Therefore, in order to obtain comprehensive research of how a leader exerts their influence on employee behaviour, more research on the interactive role of leadership behaviours and context boundary conditions should be undertaken
(Restubog et al., 2011; Xu et al. 2015). In addition, our studies enrich the theoretical interpretation of the leader influence on employees' choice to speak up or remain silent, and provides a new perspective for future research to uncover the underlying mechanism.

\section{Practical Implications}

In recent years, with the more intense competition of internal and external environments faced by organisations, and as organisational tasks have become more complicated, the frequency of destructive leadership is also increasing. Employee silence is an important tactic in workplace survival under destructive leadership, and it brings serious threats for organisations' development, especially for important issues that need to be resolved in a timely manner, as well as for key information and creativity. Employees still remain silent when they are aware of the pressure brought by the destructive leadership, which greatly affects the operation and development of the organisation, and it can have wide-ranging destructive effects on all organisational levels. Therefore, the practical implications of our research for management is to have reasonable intervention strategies and to effectively prevent and inhibit the harm and consequences of destructive leadership in the organisation.

Specifically, first, the organisation needs to construct a control system and punishment mechanism for destructive leadership. With regard to the situation when employees facing destructive leadership tend to keep silent and not report the problem, the organisation should establish a safety complaint channel to avoid employees suffering retaliation and encourage their timely feedback for problems in the workplace. Second, the organisation should provide adequate conditions and resources protection for employees, alleviate role stress brought by destructive leadership, and reduce the negative emotion and cognitive embodiment from role conflict, role ambiguity, and role overload. Meanwhile, the organisation should also explore how it can achieve the best combination of work requirements and resources so that employees can work better and maintain a good conditions so as to reduce the perception of role stress. Finally, because the influence of job complexity on destructive leadership and employee silence behaviour is consistent, managers need to fully consider the complexity of the work content and reasonably assign different tasks for different employees. With the help of job design and organisational management measures to standardise the work requirements, employees can formulate flexible work plans and have a voice, no matter what situations they are facing.

\section{Limitations and Future Research}

Although this study achieved some results, there were certain limitations that need further exploration. On the one hand, our study focused on the influence of destructive leadership on employee behaviour in the workplace, 
but it did not explore destructive leadership when it has an impact on the negative behaviour of employees outside the workplace. Recently, some experts in the field of organisational behaviour have pointed out that the encounter of employees in the workplace may lead to deviant behaviours outside the workplace, which can have an impact on their work-family relationship and work-life balance. Conversely, the encounter of employees in their social life may cause negative behaviours in the workplace and may affect their relationships with colleagues and organisations. Therefore, future research should focus on expanding the boundary of destructive leadership and analysing the role mechanism of destructive leadership on employees' behaviours in different contexts (such as internally and externally to the organisation). In particular, we advise researchers to consider the impact of destructive leadership on employees' behaviour outside the workplace, using various mediating and moderating factors.

On the other hand, future research could also carry out a comparative study of cross-cultural backgrounds; for instance, by comparing the data in a Chinese cultural background with the data from developed countries in Europe and America, and analysing differences in the data collected from various Eastern cultures in mainland China and other Eastern countries or areas (e.g., Hongkong, Macao, Taiwan, Singapore, South Korea, Japan) that are deeply affected by the Chinese cultural circle.

\section{Conclusion}

As a hot issue in the field of negative organisational behaviour, destructive leadership has been given much attention by many scholars and entrepreneurs. The article was inspired by the present literature and the circumstances of China. Combining the COR theory, role theory and job characteristics model, our research adopted both qualitative and quantitative methods to discuss the influence results and role paths of destructive leadership in the Chinese cultural background and constructed a theoretical model of the impact of destructive leadership on employee silence. After collecting and analysing the data to validate the model, we obtained the following conclusions. (1) Disruptive leadership has a significant positive impact on employee silence; the more destructive the leadership, the more the employee silence in the organisation. (2) The three dimensions of role stress had a mediating effect on destructive leadership and employee silence, and destructive leadership usually motivates employees to produce a situation of role conflict, role ambiguity and role overload, and then form employee silence. (3) Job complexity moderates the positive relationship between destructive leadership and employee silence, as well as the positive relationship between destructive leadership and the three dimensions of role stress. The role conflict, role ambiguity, and role overload from destructive leadership are more likely to cause employee silence when the job complexity is high. (4) Job complexity moderates the strength of the indirect effect of destructive leadership on employee silence via role conflict, role ambiguity and role overload, such that the mediated relationship is stronger when job complexity is high rather than low.

\section{References}

Aiken, L.S., \& West, S.G. (1991), Multiple regressions: Testing and interpreting interactions. New York, NY: Sage Publications.

Bakker, A.B., \& Demerouti, E. (2007). The job demandsresources model: State of the art. Journal of Managerial Psychology, 22, 309-328. doi:10.1108/02683940710733115

Baron, R.M., \& Kenny, D.A. (1986). The moderator-mediator variable distinction in social psychological research: Conceptual, strategic, and statistical considerations. Journal of Personality and Social Psychology, 51, 1173-1182. doi:10.1037//0022-3514.51.6.1173

Belasco, J.A. (1966). The salesman's role revisited. The Journal of Marketing, 30, 6-8. doi:10.2307/1249055

Behrman, D.N., \& Perreault, W.D. (1984). A role stress model of the performance and satisfaction of industrial salespersons. The Journal of Marketing, 48, 9-21. doi:10.2307/1251506

Bolton, L.R., Harvey, R.D., Grawitch, M.J., \& Barber, L.K. (2012). Counterproductive work behaviours in response to emotional exhaustion: A moderated mediational approach. Stress and Health, 28, 222-233. doi:10.1002/smi.1425

Brinsfield, C.T. (2013). Employee silence motives: Investigation of dimensionality and development of measures. Journal of Organizational Behavior, 34, 671-697. doi:10.1002/job.1829

Brown, S.P., \& Peterson, R.A. (1993). Antecedents and consequences of salesperson job satisfaction: Meta-analysis and assessment of causal effects. Journal of Marketing Research, 30, 63-77. doi:10.2307/3172514

Coelho, F., Augusto, M., \& Lages, L.F. (2011). Contextual factors and the creativity of frontline employees: The mediating effects of role stress and intrinsic motivation. Journal of Retailing, 87, 31-45. doi:10.1016/j.jretai.2010.11.004

Conley, S., \& You, S. (2014). Role stress revisited: Job structuring antecedents, work outcomes, and moderating effects of locus of control. Educational Management Administration \& Leadership, 42, 184-206. doi:10.1177/1741143213499264

Dale, K., \& Fox, M.L. (2008). Leadership style and organizational commitment: Mediating effect of role stress. Journal of Managerial Issues, 20, 109-130. http://www.jstor.org/stable/40604597

Dedahanov, A.T., Dedahanov, A.T., Lee, D.H., Lee, D.H., Rhee, J., \& Rhee, J. (2016). Silence as a mediator between organizational factors and stress. Journal of Managerial Psychology, 31, 1251-1264. doi:10.1108/jmp-09-2014-0265

Detert, J.R., \& Burris, E.R. (2007). Leadership behavior and employee voice: Is the door really open? Academy of Management Journal, 50, 869-884. doi:10.5465/amj.2007.26279183

Detert, J.R., \& Treviño, L.K. (2010). Speaking up to higher-ups: How supervisors and skip-level leaders 
influence employee voice. Organization Science, 21, 249-270. doi:10.1287/orsc. 1080.0405

Dyne, L.V., Ang, S., \& Botero, I.C. (2003). Conceptualizing employee silence and employee voice as multidimensional constructs. Journal of Management Studies, 40, 1359-1392. doi:10.1111/1467-6486.00384

Edmondson, A.C. (2003). Speaking up in the operating room: How team leaders promote learning in interdisciplinary action teams. Journal of Management Studies, 40, 1419-1452. doi:10.1111/1467-6486.00386

Einarsen, S., Aasland, M.S., \& Skogstad, A. (2007). Destructive leadership behaviour: A definition and conceptual model. The Leadership Quarterly, 18, 207-216. doi:10.1016/j.leaqua.2007.03.002

Farh, C. I., \& Chen, Z. (2014). Beyond the individual victim: Multilevel consequences of abusive supervision in teams. Journal of Applied Psychology, 99, 1074-1095. doi: $10.1037 / \mathrm{a} 0037636$

Fuller, J.B., Marler, L.E., \& Hester, K. (2006). Promoting felt responsibility for constructive change and proactive behavior: Exploring aspects of an elaborated model of work design. Journal of Organizational Behavior, 27, 1089-1120. doi:10.1002/job.425

Greenbaum, R.L., Mawritz, M.B., \& Piccolo, R.F. (2015). When leaders fail to 'Walk the Talk' supervisor undermining and perceptions of leader hypocrisy. Journal of Management, 41, 929-956. doi:10.1177/0149206312442386

Hackman, JR., Oldham, GR. (1975). Development of the Job Diagnostic Survey. Journal of Applied Psychology, 60, 159170. doi:10.1037/h0076546

Hackman, JR, Oldham, GR. (1980). Work redesign. Reading, MA: Addison-Wesley.

Halbesleben, J.R., Neveu, J.P., Paustian-Underdahl, S.C., \& Westman, M. (2014). Getting to the 'COR' understanding the role of resources in conservation of resources theory. Journal of Management, 40, 1334-1364. doi: $10.1177 / 0149206314527130$

Hakanen, J.J., Bakker, A.B., \& Demerouti, E. (2005). How dentists cope with their job demands and stay engaged: The moderating role of job resources. European Journal of Oral Sciences, 113, 479-487. doi:10.1111/j.1600-0722.2005.00250.x

Hayes, A.F. (2013). Introduction to mediation, moderation, and conditional process analysis: A regression-based approach. New York, NY: Guilford Press.

Hobfoll, S.E. (1989). Conservation of resources: A new attempt at conceptualizing stress. American Psychologist, 44, 513-524. doi:10.1037//0003-066x.44.3.513

Hobfoll, S.E. (2001). The influence of culture, community, and the nested-self in the stress process: Advancing conservation of resources theory. Applied Psychology, 50, 337-421. doi:10.1111/1464-0597.00062

Hofmann, W., Schmeichel, B.J., \& Baddeley, A.D. (2012). Executive functions and self-regulation. Trends in Cognitive Sciences, 16, 174-180. doi:10.1016/j.tics.2012.01.006

Hunter, J.E., Schmidt, F.L., \& Judiesch, M.K. (1990). Individual differences in output variability as a function of job complexity. Journal of Applied Psychology, 75, 28. doi:10.1037//0021-9010.75.1.28

Jackson, S.E., \& Schuler, R.S. (1985). A meta-analysis and conceptual critique of research on role ambiguity and role conflict in work settings. Organizational behavior and human decision processes, 36, 16-78. doi:10.1016/0749-5978(85)90020-2

Jung, J., Nam, C., Lee, E., \& Kim, S. (2016). Professional autonomy, group cohesion, and job complexity affect researchers' organizational commitment. Social Behavior and Personality, 44, 1349-1358. doi:10.2224/sbp.2016.44.8.1349

Kahn, R.L., Wolfe, D.M., Quinn, R.P., Snoek, J.D., \& Rosenthal, R.A. (1964). Organizational stress: Studies in role conflict and ambiguity. New York, NY: Wiley.

Kiewitz, C., Restubog, S.L.D., Shoss, M.K., Garcia, P.R.J.M., \& Tang, R.L. (2016). Suffering in silence: Investigating the role of fear in the relationship between abusive supervision and defensive silence. Journal of Applied Psychology, 101, 731-742. doi:10.1037/apl0000074

Mackey, J.D., Frieder, R.E., Brees, J.R., \& Martinko, M.J. (2015). Abusive supervision: A meta-analysis and empirical review. Journal of Management, 43, 1940-1965. doi:10.1177/0149206315573997

MacKinnon, D.P., Lockwood, C.M., \& Williams, J. (2004). Confidence limits for the indirect effect: Distribution of the product and resampling methods. Multivariate Behavioral Research, 39, 99-128. doi:10.1207/s15327906mbr3901_4

Martinko, M.J., Harvey, P., Brees, J.R., \& Mackey, J. (2013). A review of abusive supervision research. Journal of Organizational Behavior, 34( Suppl. 1), 120-137. doi:10.1002/job.1888

May, D., Wesche, J.S., Heinitz, K., \& Kerschreiter, R. (2015). Coping With Destructive Leadership. Zeitschrift für Psychologie, 222, 203-213. doi:10.1027/2151-2604/a000187

Milliken, F.J., Morrison, E.W., \& Hewlin, P.F. (2003). An exploratory study of employee silence: Issues that employees don't communicate upward and why. Journal of Management Studies, 40, 1453-1476. doi:10.1111/1467-6486.00387

Mitchell, M.S., \& Ambrose, M.L. (2007). Abusive supervision and workplace deviance and the moderating effects of negative reciprocity beliefs. Journal of Applied Psychology, 92, 1159-1168. doi:10.1037/0021-9010.92.4.1159

Mohan, G., \& Mulla, Z.R. (2013). Openness to experience and work outcomes: exploring the moderating effects of conscientiousness and job complexity. Great Lakes Herald, 7, $18-36$.

Morrison, E.W., \& Milliken, F.J. (2000). Organizational silence: A barrier to change and development in a pluralistic world. Academy of Management Review, 25, 706-725. doi: $10.2307 / 259200$

Morrison, E.W. (2011). Employee voice behavior: Integration and directions for future research. Academy of Management Annals, 5, 373-412. doi:10.1080/19416520.2011.574506

Ng, T.W., \& Feldman, D.C. (2012). Employee voice behavior: A meta-analytic test of the conservation of resources framework. Journal of Organizational Behavior, 33, 216-234. doi:10.1111/peps.12003 
Nurmi, N., \& Hinds, P.J. (2016). Job complexity and learning opportunities: A silver lining in the design of global virtual work. Journal of International Business Studies, 47, 631-654. doi:10.1057/jibs.2016.11

Organ, D.W., \& Greene, C.N. (1981). The effects of formalization on professional involvement: A compensatory process approach. Administrative Science Quarterly, 26, 237-252. doi:10.2307/2392471

Park, J.H., Carter, M.Z., DeFrank, R.S., \& Deng, Q. (2016). Abusive supervision, psychological distress, and silence: The effects of gender dissimilarity between supervisors and subordinates. Journal of Business Ethics, 11, 1-18. doi:10.1007/s10551-016-3384-3

Peterson, M.F., Smith, P.B., Akande, A., Ayestaran, S., Bochner, S., Callan, V., ... Hofmann, K. (1995). Role conflict, ambiguity, and overload: A 21-nation study. Academy of Management Journal, 38, 429-452. doi: $10.2307 / 256687$

Preacher, K.J., Rucker, D.D., \& Hayes, A.F. (2007). Addressing moderated mediation hypotheses: Theory, methods, and prescriptions. Multivariate Behavioral Research, 42, 185-227. doi:10.1080/00273170701341316

Restubog, S.L.D., Scott, K.L., \& Zagenczyk, T.J. (2011). When distress hits home: The role of contextual factors and psychological distress in predicting employees' responses to abusive supervision. Journal of Applied Psychology, 96, 713. doi:10.1037/a0021593

Rousseau, D.M. (1978). Characteristics of departments, positions, and individuals: Contexts for attitudes and behavior. Administrative Science Quarterly, 23, 521-540. doi: $10.2307 / 2392578$

Schyns, B., \& Schilling, J. (2013). How bad are the effects of bad leaders? A meta-analysis of destructive leadership and its outcomes. The Leadership Quarterly, 24, 138-158. doi:10.1016/j.leaqua.2012.09.001

Singh, D. (1993). Adaptive significance of female physical attractiveness: Role of waist-to-hip ratio. Journal of Personality and Social Psychology, 65, 293. doi:10.1037//0022-3514.65.2.293

Singh, J. (1998). Striking a balance in boundary-spanning positions: An investigation of some unconventional influences of role stressors and job characteristics on job outcomes of salespeople. The Journal of Marketing, 62, 69-86. doi: $10.2307 / 1251744$

Sorensen, J.E., \& Sorensen, T.L. (1974). The conflict of professionals in bureaucratic organizations. Administrative Science Quarterly, 19, 98-106. doi: 10.2307/2391790

Tangirala, S., \& Ramanujam, R. (2008). Employee silence on critical work issues: The cross level effects of pro- cedural justice climate. Personnel Psychology, 61, 37-68. doi:10.1111/j.1744-6570.2008.00105.x

Teas, R.K. (1983). Supervisory behavior, role stress, and the job satisfaction of industrial salespeople. Journal of Marketing Research, 20, 84-91. doi:10.2307/3151415

Tepper, B.J. (2000). Consequences of abusive supervision. Academy of Management Journal, 43, 178-190. doi: $10.2307 / 1556375$

Tepper, B.J., Moss, S.E., Lockhart, D.E., \& Carr, J.C. (2007). Abusive supervision, upward maintenance communication, and subordinates' psychological distress. Academy of Management Journal, 50, 1169-1180. doi:10.2307/20159918

Thoroughgood, C.N., Padilla, A., Hunter, S.T., \& Tate, B.W. (2012). The susceptible circle: A taxonomy of followers associated with destructive leadership. The Leadership Quarterly, 23, 897-917. doi:10.1016/j.leaqua.2012.05.007

Tierney, P., \& Farmer, S.M. (2002). Creative self-efficacy: Its potential antecedents and relationship to creative performance. Academy of Management Journal, 45, 1137-1148. doi: $10.2307 / 3069429$

Tubre, T.C., \& Collins, J.M. (2000). Jackson and Schuler (1985) revisited: A meta-analysis of the relationships between role ambiguity, role conflict, and job performance. Journal of Management, 26, 155-169. doi:10.1016/s0149-2063(99)00035-5

Vakola, M., \& Bouradas, D. (2005). Antecedents and consequences of organizational silence: an empirical investigation. Employee Relations, 27, 441-458. doi:10.1108/01425450510611997

Walker, O.C., Churchill, G.A., \& Ford, N.M. (1975). Organizational determinants of the industrial salesman's role conflict and ambiguity. The Journal of Marketing, 39, 32-39. doi:10.2307/1250800

Wang, C.J., Tsai, H.T., \& Tsai, M.T. (2014). Linking transformational leadership and employee creativity in the hospitality industry: The influences of creative role identity, creative self-efficacy, and job complexity. Tourism Management, 40, 79-89. doi:10.1016/j.tourman.2013.05.008

Whitman, M.V., Halbesleben, J.R., \& Holmes, O. (2014). Abusive supervision and feedback avoidance: The mediating role of emotional exhaustion. Journal of Organizational Behavior, 35, 38-53. doi:10.1002/job.1852

Xu, A.J., Loi, R., \& Lam, L.W. (2015). The bad boss takes it all: How abusive supervision and leader-member exchange interact to influence employee silence. The Leadership Quarterly, 26, 763-774. doi:10.1016/j.leaqua.2015.03.002

Zapf, D. (1993). Stress-oriented analysis of computerized office work. The European Work and Organizational Psychologist, 3, 85-100. doi:10.1080/09602009308408580 